\title{
Unusual Case of Idiopathic Membranous Later Developing Non-Hodgkin's Lymphoma
}

\author{
Rubina Naqvi \\ Department of Nephrology, Sindh Institute of Urology and Transplantation (SIUT), Karachi, Pakistan \\ Email: rubinanaqvi@gmail.com
}

Received 26 July 2014; revised 24 August 2014; accepted 17 September 2014

Copyright (c) 2014 by author and Scientific Research Publishing Inc.

This work is licensed under the Creative Commons Attribution International License (CC BY). http://creativecommons.org/licenses/by/4.0/

(c) 1 (i) Open Access

\begin{abstract}
A 30-year-old male presented to nephrology services as a case of nephrotic syndrome and membranous nephropathy was found on renal biopsy. He was treated for this pathology with steroid and cytotoxic drugs and remained in remission for 3 years and then presented with non Hodgkin's lymphoma.
\end{abstract}

Keywords

Nephrotic Syndrome, Idiopathic Membranous Nephropathy, Non-Hodgkin's Lymphoma

\section{Introduction}

Membranous nephropathy is among the most common causes of the nephrotic syndrome in adults, accounting for up to one-third of biopsy diagnoses. Most common form in adults is idiopathic (approximately 75 percent of cases) while secondary could be due to a variety of drugs, infections, and underlying diseases. These include gold, penicillamine, systemic lupus erythematosus, malignancy, and hepatitis B and C virus infection [1]-[3].

We aim to present here an unusual case of a young male who initially came as idiopathic membranous nephropathy, treated, got remission for 3 years and then presented with non Hodgkin's lymphoma.

\section{Case}

A 30-year-old male was referred to nephrology clinic of Sindh Institute of Urology and Transplantation, which is a tertiary care center for nephro-urological disorders. He was a farmer by profession, in rural area of province of Sindh, living at a distance of $350 \mathrm{Km}$ from this hospital, non-smoker, having history of asthma and atopic allergies for last at least 15 years, he only took salbutamol and steroid inhaler off and on for his asthma during this period and there was no history of herbal or homeopathic drug ingestion in past. Beside that he had history of acquiring pulmonary tuberculosis a year earlier, for which he received Rifampicin, Isoniazid, Ethambutol and 
Pyrazinamide based antituberculous regimen for 8 months, he did required in addition indwelling catheter in pleural cavity for drainage of pleural effusion, which remained in for 4 - 5 days. He was father of 3 and there was no positive history of any medical condition in his siblings, parents or children.

At the time of presentation to this hospital, which was July 2004, he had generalized body swelling, passage of frothy urine and malaise of 2 months duration. There was no noticeable weight loss during this period. He was started on Prednisolone in dose of $0.65 \mathrm{mg} / \mathrm{kg} /$ day and on diuretics 10 days prior to referring to this hospital.

On examination at initial presentation he was afebrile with blood pressure of 120/80, heart rate of 80 beats per minute and weight of $57 \mathrm{Kg}$. He had bilateral pedal edema to the knees, periorbital swelling, no rash, no lymphadenopathy and normal jugular venous pressure. Abdomen was soft with ascitis and no organomegaly. Lungs auscultation revealed occasional fine basal crackles. Heart examination revealed regular rate and rhythm with no murmurs. Loco motor and nervous system examination was unremarkable.

Initial laboratory tests revealed Hemoglobin of 11.5, hematocrit 34, TLC 8, platelet 234, ESR 15 mm 1st hour, urea $18 \mathrm{mg} / \mathrm{dl}$, creatinine $0.8 \mathrm{mg} / \mathrm{dl}$, K 4.2, Na 139, Ca $7.0 \mathrm{mg} / \mathrm{dl}$, albumin $1.4 \mathrm{~g} / \mathrm{dl}$, random blood sugar 121 $\mathrm{mg} / \mathrm{dl}$, liver enzymes and bilirubin were in normal limits, urinalysis revealed specific gravity of 1025, albumin 3+, no red cells, white cells, casts or crystal. 24 hours urinary protein excretion was 3.1 Gm. Abdominal sonography revealed normal size non hydronephrotic both kidneys, normal spleen and pancreas, thick walled gall bladder, mild hepatomegaly and minimal ascitis. Renal veins were patent bilaterally. Chest roentgenogram was unremarkable except for blunt right cardio phrenic angle. Echocardiography showed normal chambers and valves with mild pericardial effusion. Serological tests revealed within normal range immunoglobulins (IgA, IgG, and IgM) and complement levels (C3 and C4) and negative HbsAg, AntiHCV, ANA, AntiDNA, ASOT, RA factor and ANCA. Renal biopsy was initially postponed as he went in remission on steroids he was started before coming to us, which were tapered to stop at 4 months duration. He came in relapse in May 2005 and this time renal biopsy was done which showed membranous thickening and spikes (Figure 1).

After routine laboratory and radiological tests, diagnosis of idiopathic membranous nephropathy was made and he was started on diuretic, ARB, Prednisolone from $0.5 \mathrm{mg} / \mathrm{kg} / \mathrm{day}$ and cyclophosphamide $2 \mathrm{mg} / \mathrm{kg} / \mathrm{day}$ (cumulative dose of $160 \mathrm{mg} / \mathrm{Kg}$ ). Steroid tapered to stop over 4 months. Edema disappeared at 4 weeks and proteinuria disappeared completely by 7 weeks of start of treatment.

This man remained in remission while examined in outpatient clinic in Jan. 2006, then June 2006. In Mar. 2007 he came to us with fever and productive cough of 10 days duration, was afebrile when examined, had no enlarged lymph-nodes, bilateral lower zone crackles over auscultation of lungs. He was still in remission, sputum was unremarkable. Chest roentgenogram reported as having opacifications in both lower lung fields suggestive of pulmonary infection. He was assessed by pulmonologist and given Levofloxacin and Klarithromycin for 10 days.

He returned in June 2007 with history of intermittent fever of 3 weeks duration, found afebrile in clinic, on chest auscultation right lower zone coarse crackles, and again treated with Levofloxacin.

His clinic follow up in May 2008 was unremarkable with no protein in urine and no active complaint. In Dec. 2008, he came with swelling of right eye with decrease in vision in this eye, fever with productive cough and significant weight loss over 2 - 3 weeks.

On examination found afebrile with blood pressure of 110/80, heart rate of 95 BPM had palpable cervical and preauricular lymph nodes on right side, which were mobile and non-tender. His right eye was bulged out, had mobility in all directions, conjunctiva was congested and pupils were non reactive. Intra ocular pressure was normal but visual acuity was reduced to 6/60. Left eye was normal.

Systemic examination revealed hepato-spleenomegaly, bilateral coarse crackles over lungs, no cardiac murmur, intact higher mental function and motor and sensory, except for local abnormality in right eye described earlier.

Routine laboratory tests were Hemoglobin 12, HCT 38, TLC 10 (N = 15\%, L = 80\%), Anisocytosis, normochromic, ESR 5 mm 1st hour, urea 19 mg/dl, creatinine 1 mg/dl, K 4.2, Na 140, Ca 7.8 mg/dl Alb 2.4 liver enzymes normal, Alk. phos. 75, LDH 176 IU/L (ref. range 90 - 180). Urinalysis specific gravity of 1020, no albumin, red blood cells, white blood cells, or casts. Cultures from urine blood and sputum found negative. Sputum also looked for acid fast bacilli on 3 occasions found negative.

On radiological work up chest roentgenogram showed wide mediastinum, CT chest showed mediastinal lymphadenopathy and patchy consolidation in basal segments of lower lobes, differential included lymphoma and 

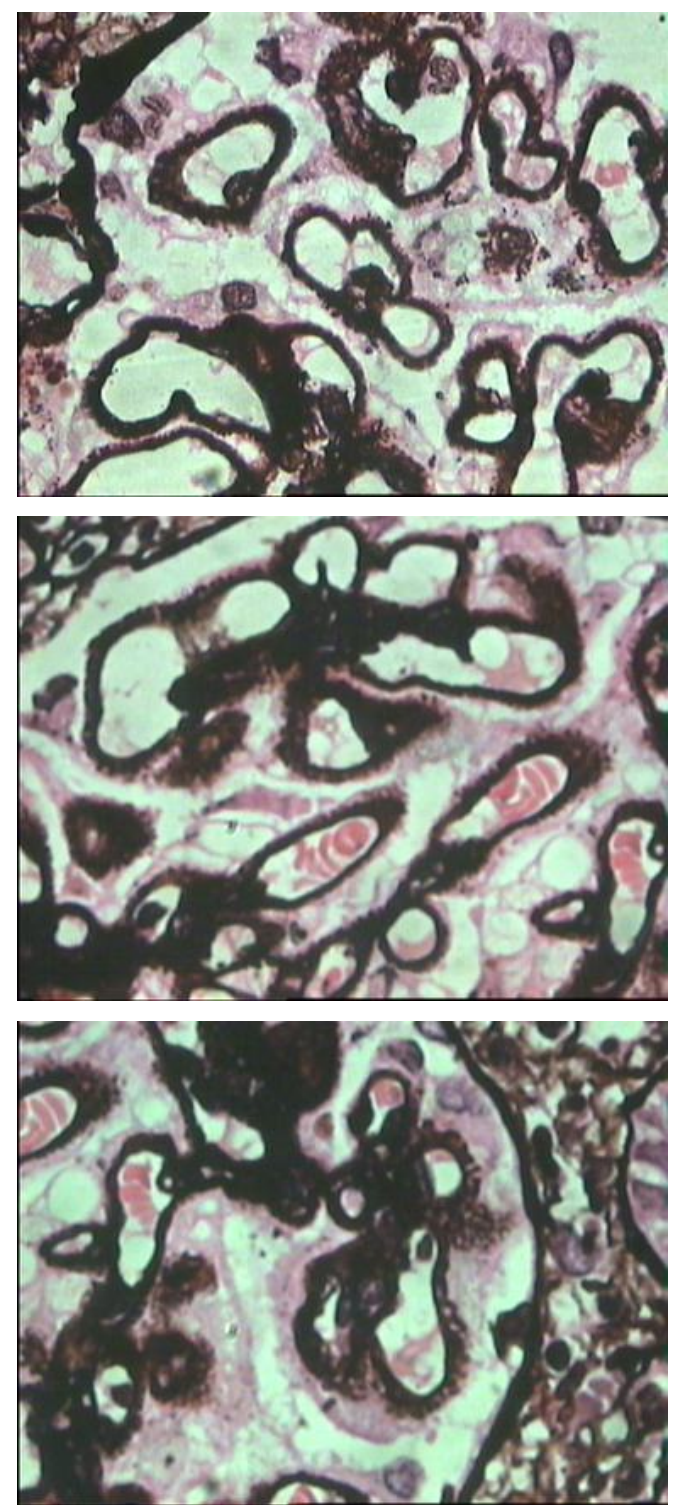

Figure 1. Renal biopsy low and medium power view of silver stain.

Wegener's (Figure 2). Abdominal CT revealed hypo dense area in upper pole of right kidney and multiple mesenteric, Para-aortic and inguinal lymph nodes of variable size (Figure 3). MRI head revealed soft tissue mass in right orbit (Figure 4).

Fluorescent Angiography revealed retinal detachment and area of hyper florescence with a small area of hypo-florescence in it (Figure 5).

Lymph node biopsy was performed which revealed diffuse sheets of small and medium size lymphoid cells (Figure 6). Tumor markers showed positivity of CD20 and scattered background cells were also positive for CD3 and CD138.

Bone Marrow biopsy performed which revealed hyper active marrow.

Patient received 4 cycles of CHOP (Jan., Feb., Mar., Apr. 2009), he tolerated cycles acceptably well except for transient decrease in cell line and derangement in renal function. He was last discharged from hospital on 16th Apr. 2009, with Hemoglobin of 11.3, TLC 10.1, Platelet 501 and serum creatinine 0.78. He was advised to come back for 5th cycle of chemotherapy scheduled for 5th May 2009, which he never did. When contacted on his cell number some relative informed that he died in quite after 2 weeks of leaving from hospital. 


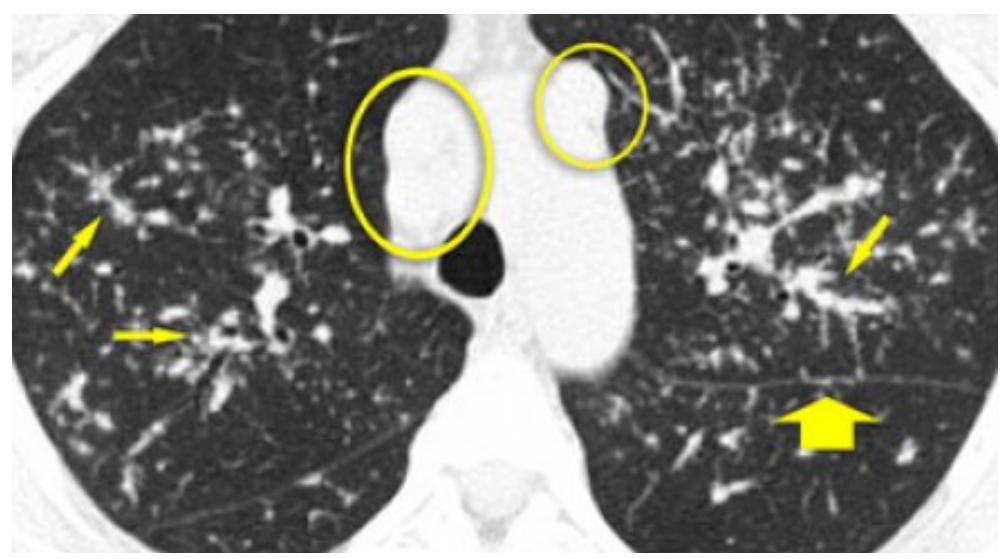

Figure 2. CT chest showing mediastinal enlarged lymph nodes and bilateral nodular infiltrates.

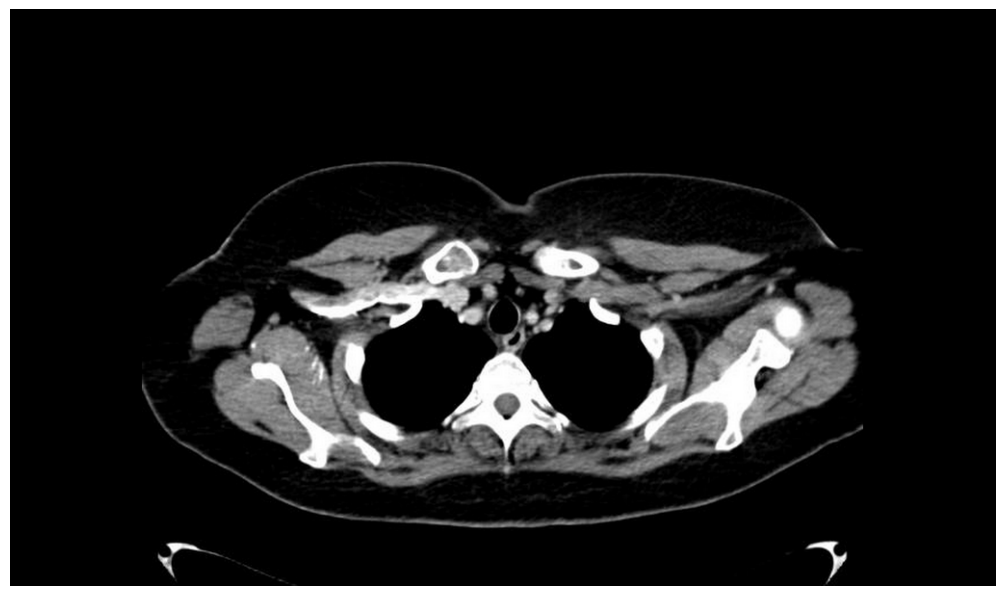

Figure 3. CT abdomen multiple enlarged lymph nodes.

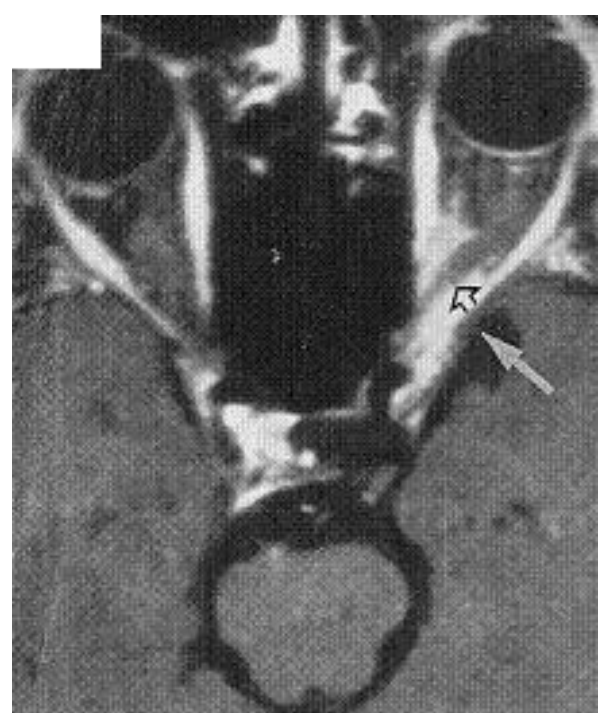

Figure 4. MRI brain after gadolinium enhancement reveals mass at the apex of the orbit (white arrow), causing displacement of optic nerve sheath (plain arrow). 


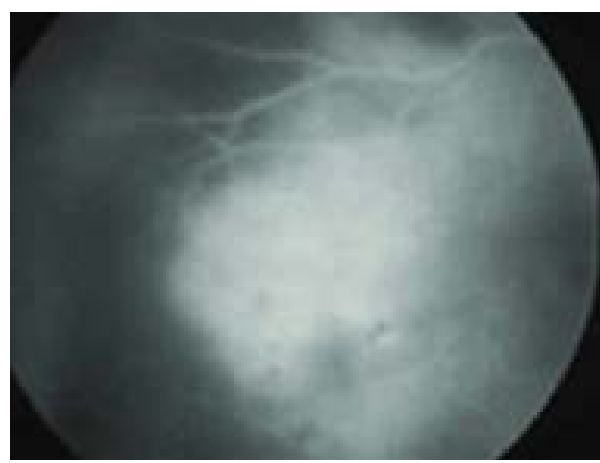

Florescent angiogram venous phase

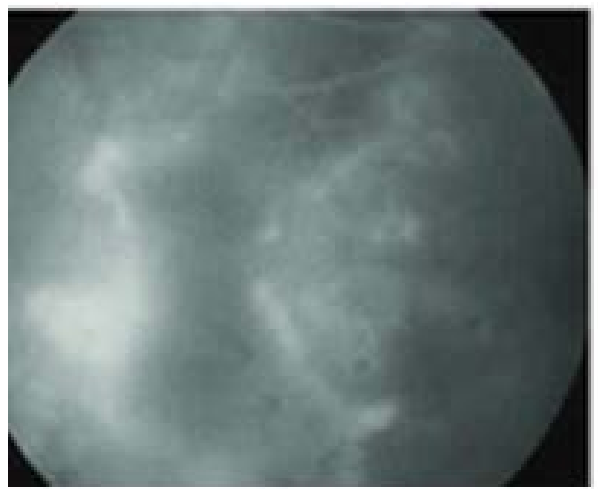

Florescent angiogram recirculation phase

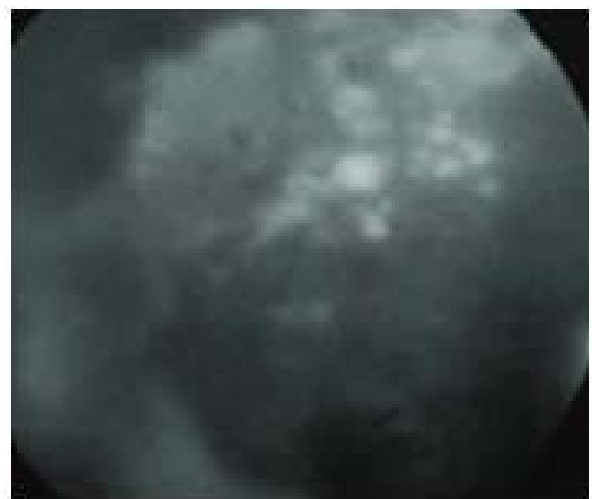

Florescent angiogram late phase

Figure 5. Lymphomatous sub retinal infiltrate.

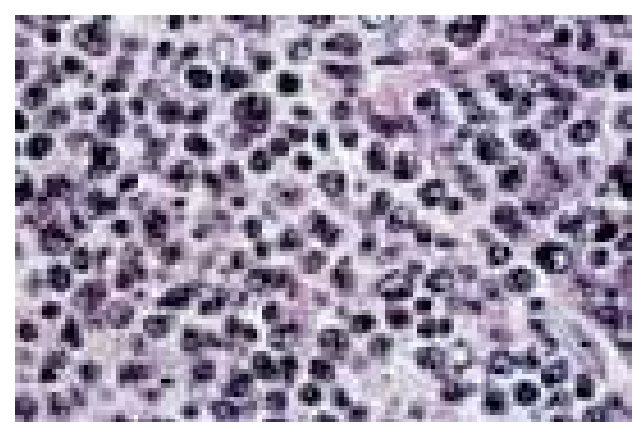

Figure 6. Lymph node biopsy diffuse lymphocytic infiltrates. 


\section{Discussion}

Over 50 years ago David Jones identified the pathologic features of membranous nephropathy (MN); distinguishing it from other causes of nephrotic syndrome [4]. MN is characterized by uniform thickening of glomerular capillary wall which is caused by sub-epithelial deposits of immune complexes. In about two third of cases the etiology of MN is unknown and disease is called as idiopathic MN(IMN) [1]. IMN remains the most common cause of nephrotic syndrome in adults [2] [3]. Management of MN remained a topic of debate since early 1970s and consensus regarding therapy remains a question. Remuzzi et al. have published a review on immunosuppressive (IS) therapy for IMN, they included all randomized controlled trials (RCTs) on IS searching literature according to Cochrane Collaboration guidelines [5]. Their searches on 18 RCTs (1025 patients) proved no difference between IS therapy and placebo or no treatment group. Groups included here were steroid alone, alkylating agent alone or in combination with steroid, calcineurin inhibitor alone or in combination with steroid and anti-proliferative agent alone [5]. Whereas, a study from region (RCT) has proven favorable long term results of use of combination of steroid and cytotoxic in IMN [6]. As IMN is diagnosis of exclusion, a search for secondary causes of MN is a routine. History of NSAIDs, Solvents, Gold salts, Serological examination for HBV, HCV, SLE and radiological screening to evaluate any cancer are usual in any nephrology setting.

Published reports cite membranous nephropathy as the most common malignancy-associated glomerulopathy, occurring with many carcinomas and occasionally with leukemia and lymphoma [7].

Non-Hodgkin's lymphomas are a heterogeneous group of neoplasm arising from the lymphopoietic system including a wide range of subtypes of either B-cells or T-cells lymphomas. The few established risk factors for the development of these neoplasms include viral infections and immunological abnormalities, but their etiology remains largely unknown.

The immunomodulators can exhaust cytotoxic $\mathrm{T}$ lymphocytes and induce an imbalance in the control of EBV infection thus giving EBV associated B Cell lymphoma [8] [9]. We have not assessed EBV status in our patient, though our $90 \%$ general population is IgM positive for EBV (unpublished data).

Renal involvement as part of systemic lymphoma is quite frequent and most common presentation is with acute renal failure, glomerulonephritis has also rarely been reported in association with lymphoma [10].

A case of diffuse large B cell lymphoma been reported recently after treatment for aplastic anemia which was consisted of anti-thymocyte globulin and cyclosporine [11].

Our patient was a unique presentation; he initially had only IMN received cytotoxic and steroid combination therapy and after 3 years came with B cell non-Hodgkin's lymphoma. During this period he was coming up regularly and never raised any suspicion of lymphoproliferative disease. His interim presentation with respiratory symptoms could be any viral infection, which is all hypothetical. Reported prognosis of lymphoma with CHOP therapy is reasonably good but this patient was unfortunate enough of not having medical facilities available at his near distance.

\section{Conclusion}

More than one pathology can always exist, or one occurring after it should be kept in mind. Poor health care facilities in developing world continue to result in loss of young lives.

\section{References}

[1] Pontecelli, C. (2007) Membranous Nephropathy. Journal of Nephrology, 20, 268-287.

[2] Cattarn, D.C. (2002) Membranous Nephropathy: Quo Vadis? Kidney International, 61, 349-350. http://dx.doi.org/10.1046/j.1523-1755.2002.00125.X

[3] Fervenza, F.C., Sethi, S. and Specks, U. (2008) Idiopathic Memranous Nephropathy: Diagnosis and Treatment. Clinical Journal of the American Society of Nephrology, 3, 905-919. http://dx.doi.org/10.2215/CJN.04321007

[4] Jones, D.B. (1957) Nephrotic Glomerulonephritis. American Journal of Pathology, 33, 313-329.

[5] Perna, A., Schieppati, A., Zamora, J., Giuliano, G.A., Braun, N. and Remuzzi, G. (2004) Immunnosuppressive Therapy for Idiopathic Memranous Nephropathy: A Systemic Review. American Journal of Kidney Diseases, 44, 385-401. http://dx.doi.org/10.1053/j.ajkd.2004.05.020

[6] Jha, V., Gangoli, A., Saha, T.K., Sud, K., Gupta, K.L., Joshi, K. and Sakhuja, V. (2007) A Randomized, Controlled Trial of Steroid and Cyclophosphamide in Adults with Nephrotic Syndrome Caused by Idiopathic Memranous Nephropathy. Journal of the American Society of Nephrology, 18, 1899-1904. http://dx.doi.org/10.1681/ASN.2007020166 
[7] Gupta, K., Nada, R., Das, A. and Kumar, M.S. (2008) Membranoproliferative Glomerulonephritis in a Carcinoma with Unknown Primary: An Autopsy Study. Indian Journal of Pathology and Microbiology, 51, 230-233. http://dx.doi.org/10.4103/0377-4929.41665

[8] Richendollar, B.G., His, E.D. and Cook, J.R. (2009) Extramedullary Plasmacytoma like Posttransplantation Lymphoproliferative Disorders: Clinical and Pathological Features. American Journal of Clinical Pathology, 132, 581-588. http://dx.doi.org/10.1309/AJCPX70TIHETNBRL

[9] Hasserjian, R.P., Chen, S., Perkin, S.L., del Leval, L., Kinney, M.C., Barry, T.S., Said, J., Lim, M.S., Finn, W.G., Medeiros, L.J., Harris, N.L. and O’Malley, D.P. (2009) Immunomodulator Agent Related Lymphoproliferative Disorders. Modern Pathology, 22, 1532-1540.

[10] Da'as, N., Polliak, A., Cohen, Y., Amir, G., Darmon, D., Kleinman, Y., Goldfarb, A.W. and Ben-Yahuda, D. (2001) Kidney Involvement and Renal Manifestation in Non-Hodgkin's Lymphoma and Lymphocytic Leukemia: A Retrospective Study in 700 Patients. European Journal of Haematology, 67, 158-164. http://dx.doi.org/10.1034/j.1600-0609.2001.5790493.x

[11] Suzuki, Y., Niitsu, N., Hayama, M., Katayama, T., Ishii, R., Osaka, M., Miyazaki, K., Danbara, M., Horie, R., Yoshida, T., Nakamura, N. and Higashihara, M. (2009) Lymphoproliferative Disorders after Immunosuppressive Therapy for Aplastic Anemia: A Case Report and Literature Review. Acta Haematologica, 121, 21-26. http://dx.doi.org/10.1159/000209225 
Scientific Research Publishing (SCIRP) is one of the largest Open Access journal publishers. It is currently publishing more than 200 open access, online, peer-reviewed journals covering a wide range of academic disciplines. SCIRP serves the worldwide academic communities and contributes to the progress and application of science with its publication.

Other selected journals from SCIRP are listed as below. Submit your manuscript to us via either submit@scirp.org or Online Submission Portal.
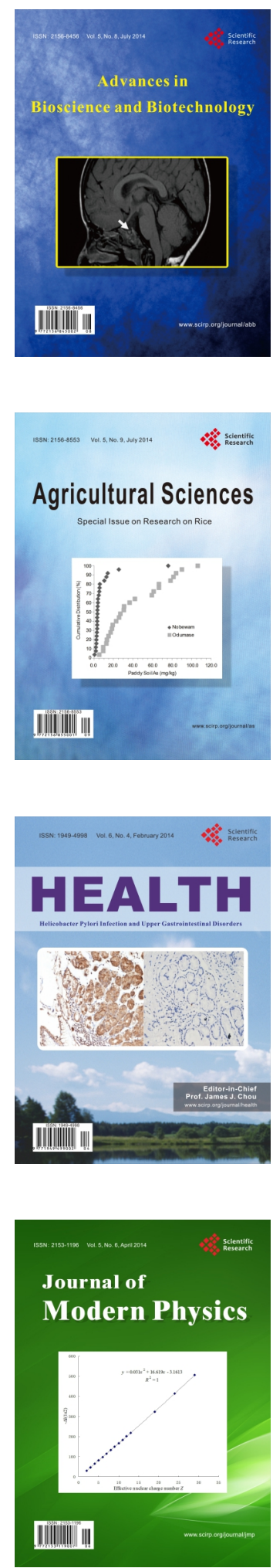
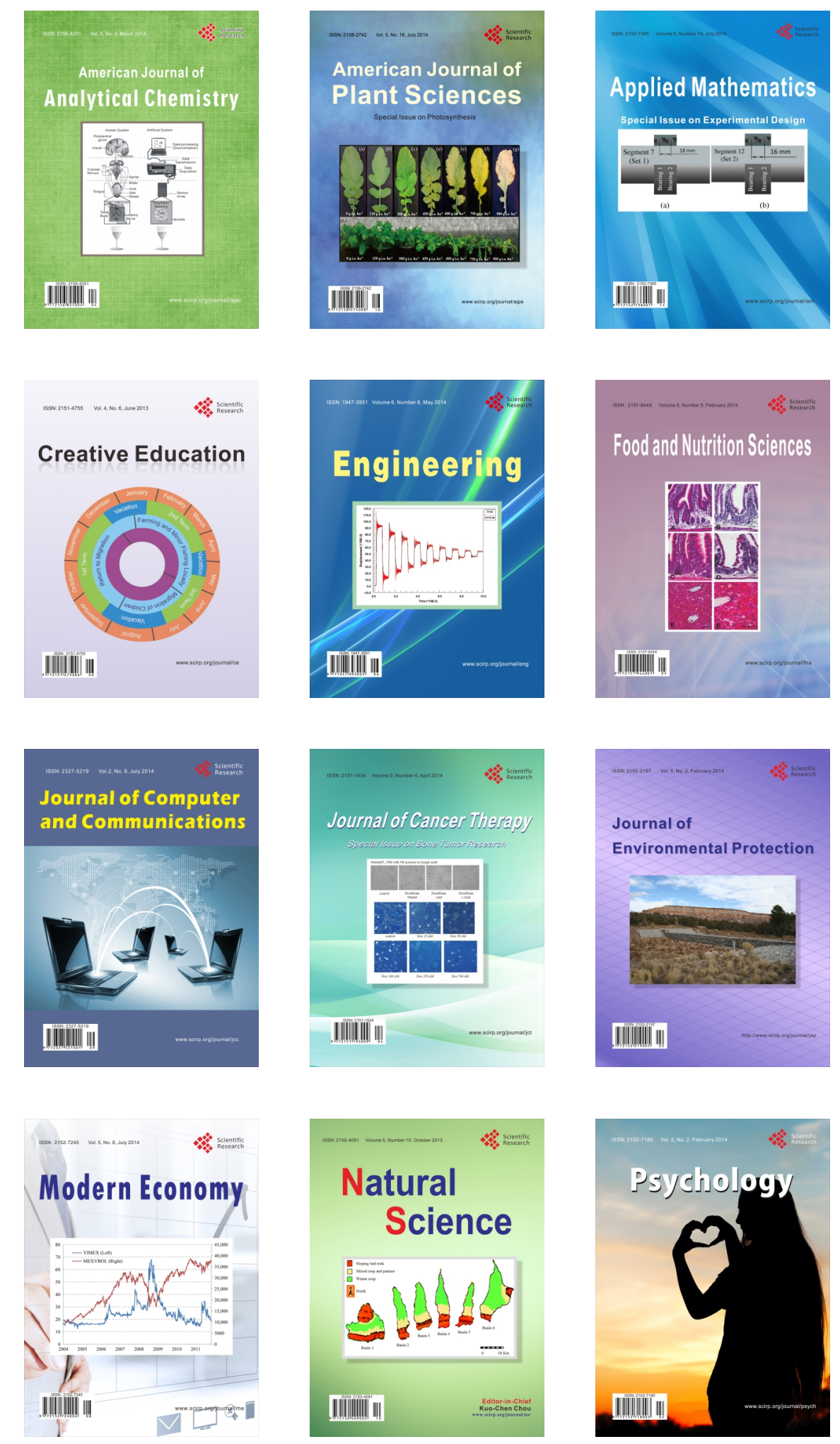